\title{
Studies on Biosorption of Methylene Blue from Aqueous Solutions by Powdered Palm Tree Flower (Borassus flabellifer)
}

\author{
M. Srinivas Kini, ${ }^{1}$ M. B. Saidutta, ${ }^{2}$ and V. Ramachandra Murty ${ }^{3}$ \\ ${ }^{1}$ Department of Chemical Engineering, Manipal Institute of Technology, Manipal 576104, India \\ ${ }^{2}$ Department of Chemical Engineering, National Institute of Technology Karnataka, Surathkal 575025, India \\ ${ }^{3}$ Department of Biotechnology, Manipal Institute of Technology, Manipal 576104, India
}

Correspondence should be addressed to M. Srinivas Kini; srinivas_kini@rediffmail.com

Received 18 September 2013; Accepted 25 November 2013; Published 2 February 2014

Academic Editor: Jean-Pierre Corriou

Copyright (C) 2014 M. Srinivas Kini et al. This is an open access article distributed under the Creative Commons Attribution License, which permits unrestricted use, distribution, and reproduction in any medium, provided the original work is properly cited.

\begin{abstract}
Biosorption experiments were carried out for the removal of methylene blue (MB) using palm tree male flower (PTMF) as the biosorbent at various $\mathrm{pH}$, temperature, biosorbent, and adsorbate concentration. The optimum $\mathrm{pH}$ was found to be 6.0. The kinetic data were fitted in pseudofirst-order and second-order models. The equilibrium data were well-fitted in Langmuir isotherm and the maximum equilibrium capacities of the biosorbent were found to be $143.6,153,9,157.3 \mathrm{mg} / \mathrm{g}$ at 303 , 313, and $323 \mathrm{~K}$, respectively. Thermodynamic data for the adsorption system indicated spontaneous and endothermic process. The enthalpy and entropy values for adsorption were obtained as $15.06 \mathrm{KJ} / \mathrm{mol}$ and $0.129 \mathrm{KJ} / \mathrm{mol} \mathrm{K}$, respectively, in the temperature range of $303-323 \mathrm{~K}$. A mathematical model for MB transported by molecular diffusion from the bulk of the solution to the surface of PTMF was derived and the values of liquid phase diffusivity and external mass transfer coefficient were estimated.
\end{abstract}

\section{Introduction}

Dyes are widely used in industries such as textiles, rubber, cosmetic, paper, carpet, printing, and leather and are wellknown pollutants of receiving bodies in the industrial areas. The release of dyes into waste waters by various industries causes serious environmental problems due to their toxicity and carcinogenicity and this poses a serious hazard to aquatic living organism [1]. However, waste water with dyes is very difficult to treat, since the dyes are recalcitrant organic molecules, are resistant to aerobic digestion, and are stable to light, heat, and oxidizing agents [2]. Methylene blue (MB) is not regarded as acutely toxic, but it can cause various harmful effects such as nausea, vomiting, diarrhea, gastritis, abdominal, chest pain, severe headache, profuse micturition, and methemoglobinemia-like syndrome [3].

The most commonly used methods for color removal are biological and chemical precipitation. However, these processes are effective and economical only in cases where solute concentrations are relatively high [4]. In the case of relatively low concentration, adsorption is considered to be superior to other techniques due to its low cost, simplicity of design, high efficiency, and ease of operation [5]. Adsorption on activated carbon has been shown to be very effective for removal of dyes and other pollutants from aqueous solutions due to its large surface area, microporous structure, high adsorption capacity, and so forth. However, its commercial use is limited because of its high cost of manufacturing and problems associated with regeneration or disposal of spent carbon [6].

In recent times, there has been increased interest in the use of plant waste products for dye removal by adsorption from aqueous solution because of their natural availability and higher removal efficiency. Many researchers have studied the adsorption of methylene blue dye using plant waste such as peanut hull [7], castor seed shell [8], coconut shell [9], guava leaf [10], neem leaf [3], phoenix tree leaf powder [11], teak tree bark powder [12], and gulmohar plant [13]. Plant wastes are lignocellulosic materials that consist of three main structural components which are lignin, cellulose, and hemicelluloses [14]. 
In the present study, palm tree flower (male) was used as biosorbent for removal of $\mathrm{MB}$. Palm tree male flower (PTMF) is an inexpensive and abundantly available material. Batch studies were carried out involving process parameters such as $\mathrm{pH}$, biosorbent dosage, initial dye concentration, and temperature. The influence of these parameters on adsorption capacity was investigated. The adsorption data were fitted using suitable isotherm. A new mathematical model was derived and the values of liquid phase diffusivity and external mass transfer coefficient were estimated.

\section{Mathematical Model}

Since the particle is small, the flow in the vicinity of the particle is not turbulent. Thus we assume that the mass transfer to the particle can be modeled as a process of diffusion in a quiescent medium. Assuming pseudosteady state, the differential equation is

$$
\frac{\left(1 / r^{2}\right) d\left(r^{2} d c / d r\right)}{d r}=0
$$

Solving this equation with boundary condition,

$$
\text { B.C.: } \begin{aligned}
c & =c_{\infty}, \quad r=\infty, \\
c & =c_{s}, \quad r=R,
\end{aligned}
$$

where $c_{\infty}$ is the concentration in bulk phase. The concentration profile in the liquid is obtained as

$$
c=\frac{c_{\infty}-\left(c_{\infty}-c_{s}\right) R}{r} .
$$

The flux at the surface $(r=R)$ is obtained as $D_{L}\left(c_{\infty}-c_{s}\right) / R$. This corresponds to a mass transfer coefficient $K_{c}(\mathrm{~m} / \mathrm{s})$ :

$$
K_{c}=\frac{D_{L}}{R}
$$

where $D_{L}$ is the liquid phase diffusivity $\left(\mathrm{m}^{2} / \mathrm{s}\right)$.

Material balance for the solute is

$$
\Phi\left(\frac{d q}{d t}\right)=-\frac{d c}{d t}
$$

Further, rate of accumulation of solute on the solid is equal to the rate of mass transfer from the liquid; that is,

$$
\left(\frac{d q}{d t}\right) \rho R^{2}=D_{L}\left(c-c_{s}\right) .
$$

Since equilibrium prevails on the surface, $c_{s}$ and $q$ are related by the Langmuir isotherm.

The Langmuir isotherm is given by

$$
\frac{q}{q_{m}}=\frac{b c_{s}}{\left(1+b c_{s}\right)}
$$<smiles>CN(C)c1ccc2nc3ccc(N(C)C)cc3[s+]c2c1</smiles>

FIGURE 1: Structure of methylene blue.

Therefore $c_{s}$ in (6) can be substituted in terms of $q$. Thus we obtain (8). Using (5) in (8), we obtain (9):

$$
\begin{gathered}
\frac{d q}{d t}=\left(\frac{D_{L}}{R^{2} \rho}\right)\left(\frac{c-q}{\left(b\left(q_{m}-q\right)\right)}\right), \\
\frac{d c}{d t}=-\Phi\left(\frac{D_{L}}{R^{2} \rho}\right)\left(\frac{c-q}{\left(b\left(q_{m}-q\right)\right)}\right),
\end{gathered}
$$

where $\Phi$ is solid loading $\left(\mathrm{kg} / \mathrm{m}^{3}\right.$ of liquid) and $c_{s}$ is concentration on the biosorbent surface $\left(\mathrm{kg} / \mathrm{m}^{3}\right)$.

Solving (8) and (9) as an initial value problem using initial condition $c=c_{\infty} ; q=0 ; t=0,0<r<R$, with a help of numerical computer program in MATLAB, yields the bulk concentration as a function of time. The liquid phase diffusion coefficient $D_{L}$ is obtained by matching the experimental concentration decay curve with that obtained from the model.

\section{Materials and Methods}

3.1. Adsorbate. Methylene blue (C.I. name: basic blue 9, class: Thiazine and C.I. number: 52015) is a cationic dye with a molecular formula $\mathrm{C}_{16} \mathrm{H}_{18} \mathrm{~N}_{3} \mathrm{SCl}$ and molecular weight of $319.9 \mathrm{~g} / \mathrm{mol}$ and was purchased from Himedia, Bangalore. The MB (>99\% dye content) was chosen because of its known strong adsorption onto solids. The maximum absorption wavelength of this dye is $665 \mathrm{~nm}$. The structure of MB is shown in Figure 1.

3.2. Preparation of Biosorbent. Palm tree male flower (PTMF) collected from a farmhouse in Udupi, India was washed thoroughly with distilled water to remove surface adhered particles and water soluble materials. The PTMF was dried at $70^{\circ} \mathrm{C}$ for 2 days in a hot air oven and then cut into pieces, ground in a ball mill, and sieved to obtain average particles of $150 \mu \mathrm{m}$. The PTMF powder was stored in an air tight container for further use. No other chemical treatments were used prior to adsorption experiments.

3.3. Characteristics of PTMF. The surface area and total pore volume of PTMF were determined using BET apparatus (Smart Instruments, Mumbai). The surface functional groups of PTMF were detected by Fourier transform infrared (FTIR) spectroscope (Shimadzu, Japan). About $150 \mathrm{mg} \mathrm{KBr}$ disks containing 2\% of PTMF sample were prepared before recording the FT-IR spectra in the range $450-4000 \mathrm{~cm}^{-1}$ with $16 \mathrm{~cm}^{-1}$ resolution. 
The zero point charge was determined by suspending $1.0 \mathrm{~g}$ of the PTMF in 1 millimol/L $\mathrm{NaNO}_{3}$ solution for $24 \mathrm{~h}$. Sixty milliliters of the suspension was measured into each of the eight conical flasks and the initial $\mathrm{pH}$ was adjusted to 2.14, $3.06,4.1,5.18,6.14,7.6,8.48$, and 9.22. The suspension in each of the flasks was divided into 4 equal parts and $0.3 \mathrm{~g}$ of $\mathrm{NaNO}_{3}$ was added to two sets, while the other pair contained no added nitrate. They were left for $6 \mathrm{~h}$ and after this the $\mathrm{pHs}$ of the reference and test suspensions were taken as initial and final $\mathrm{pHs}$, respectively. The pairs containing no added nitrate were taken as the reference, while those with added nitrate were taken as the test samples [15]. The results were plotted as $\mathrm{dpH}$ against initial $\mathrm{pH}\left(\mathrm{pH}_{f}\right)$.

\subsection{Biosorption Experiment}

3.4.1. Effect of $p H$. The effect of $\mathrm{pH}$ on amount of color removal was analyzed over a $\mathrm{pH}$ range of $2-9$. The $\mathrm{pH}$ was adjusted using $0.1 \mathrm{~N} \mathrm{HCl}$ and $0.1 \mathrm{~N} \mathrm{NaOH}$ solutions. In this study $100 \mathrm{~mL}$ of dye solution of $200 \mathrm{mg} / \mathrm{L}$ was agitated with $0.3 \mathrm{~g}$ of PTMF powder at room temperature of $30^{\circ} \mathrm{C}$. Agitation was carried out for $6 \mathrm{~h}$ which is more than sufficient to reach equilibrium at constant agitation of $150 \mathrm{rpm}$. The samples were then filtered and analyzed using double beam U-V spectrophotometer (UV-1700, Shimadzu, Japan) by monitoring the absorbance at a wavelength of maximum absorbance of $665 \mathrm{~nm}$.

3.4.2. Biosorbent Dosage. The effect of PTMF concentration on the amount of color adsorbed was studied by dissolving various quantities $(0.05,0.1,0.15,0.2,0.25$, and $0.3 \mathrm{~g})$ of biosorbent in $100 \mathrm{~mL}$ of dye solution of initial dye concentration of $200 \mathrm{mg} / \mathrm{L}$. All the experiment was carried out at $30^{\circ} \mathrm{C}$, $\mathrm{pH}$ of 6 , and $150 \mathrm{rpm}$ for $6 \mathrm{~h}$.

3.4.3. Biosorption Equilibrium. The equilibrium experiments were carried out at $150 \mathrm{rpm}$ by adding $0.3 \mathrm{~g}$ of PTMF powder to $100 \mathrm{~mL}$ dye solution. The dye concentration was varied from $50-300 \mathrm{mg} / \mathrm{L}$. The amount of MB adsorbed per gram $\operatorname{PTMF}\left(q_{e}\right)$ was obtained using the following expression:

$$
q_{e}=\frac{V\left(C_{0}-C_{e}\right)}{1000 M},
$$

where $q_{e}$ is the equilibrium uptake value $(\mathrm{mg} / \mathrm{g}), V$ is the sample volume $(\mathrm{L}), C_{0}(\mathrm{mg} / \mathrm{L})$ is the initial $\mathrm{MB}$ concentration, $C_{e}(\mathrm{mg} / \mathrm{L})$ is the equilibrium $\mathrm{MB}$ concentration, and $M(\mathrm{~g})$ is the dry weight of the PTMF powder. The percentage removal of the dye is given by

$$
\% \text { Removal }=100 * \frac{\left(C_{0}-C_{e}\right)}{C_{0}} .
$$

3.4.4. Biosorption Kinetics. Kinetic experiments were carried out by adding $0.3 \mathrm{~g}$ of PTMF powder to $100 \mathrm{~mL}$ of the dye solution at $30^{\circ} \mathrm{C}$ at an optimum $\mathrm{pH}$ of 6 and at $150 \mathrm{rpm}$. The dye concentration was varied from $50-200 \mathrm{mg} / \mathrm{L}$. The amount

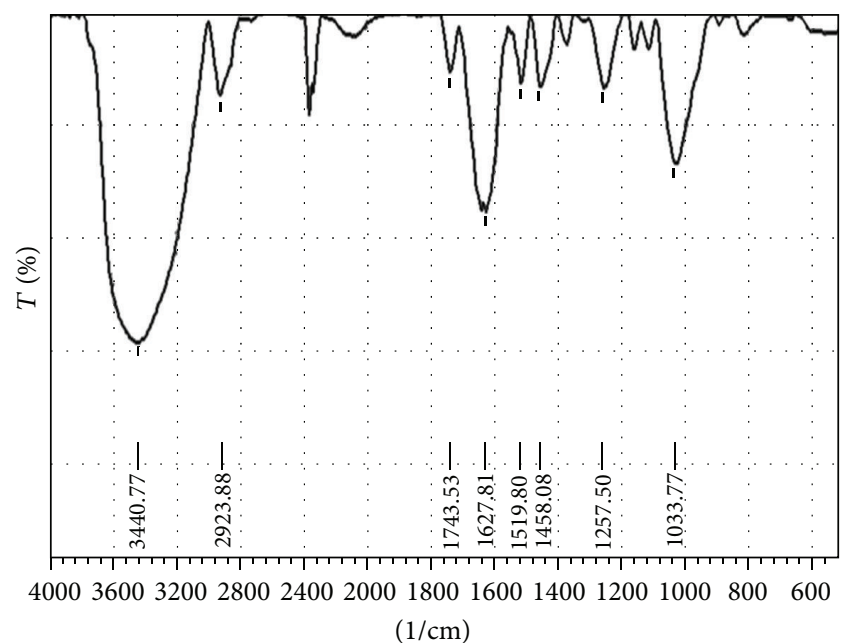

FIGURE 2: FT-IR spectra of palm tree male flower before MB adsorption.

of MB adsorbed per gram PTMF $\left(q_{t}\right)$ was obtained using the following expression

$$
q_{t}=\frac{V\left(C_{t}-C_{0}\right)}{1000 M}
$$

where $q_{t}(\mathrm{mg} / \mathrm{g})$ is the uptake value at any time $t$ and $C_{t}$ $(\mathrm{mg} / \mathrm{L})$ is the liquid-phase concentration at any time $t$.

3.4.5. Effect of Initial MB Concentration. Equilibrium experiments were carried out by mixing $0.3 \mathrm{~g}$ of PTMF powder with $100 \mathrm{~mL}$ of MB solution of different initial dye concentration ranging from $50-300 \mathrm{mg} / \mathrm{L}$. The studies were carried out at three temperatures $(303 \mathrm{~K}, 313 \mathrm{~K}$, and $323 \mathrm{~K})$ using shaking incubator. After $6 \mathrm{~h}$ the samples were filtered and analyzed for residual MB. All experiments were carried out in duplicate under identical conditions and mean values are presented. The error obtained was $2.0-4.0 \%$.

\section{Results and Discussion}

4.1. Characterization of Biosorbent. The BET surface area and total pore volume of PTMF were found to be $1.6 \mathrm{~m}^{2} / \mathrm{g}$ and $2.8 \mathrm{~m}^{3} / \mathrm{g}$, respectively. Figure 2 shows the FT-IR spectrum of PTMF biosorbent. The absorptions with maxima at $3440 \mathrm{~cm}^{-1}$ represent $\mathrm{OH}$ stretching of phenol group of cellulose and lignin and the band about $2924 \mathrm{~cm}^{-1}$ indicates presence of $-\mathrm{CH}_{2}$ stretching of aliphatic compound [16]. The peak at $2300 \mathrm{~cm}^{-1}$ is due to $\mathrm{NH}$ stretch. The band observed at $1744 \mathrm{~cm}^{-1}$ was assigned to a $\mathrm{C}=\mathrm{O}$ stretching of aldehyde [16], while the peak at $1628 \mathrm{~cm}^{-1}$ was attributed to $\mathrm{C}=\mathrm{C}$ stretching of phenol group [17]. The band at $1520 \mathrm{~cm}^{-1}$ was due to secondary amine group [18]. The band at $1458 \mathrm{~cm}^{-1}$ was due to aromatic ring of lignin. The band in $1258 \mathrm{~cm}^{-1}$ was due to bending modes of $\mathrm{O}-\mathrm{C}-\mathrm{H}, \mathrm{C}-\mathrm{C}-\mathrm{H}$, and $\mathrm{C}-\mathrm{O}-\mathrm{H}$. The band at $1033 \mathrm{~cm}^{-1}$ was assigned to $\mathrm{C}-\mathrm{O}$ stretching which confirmed the presence of lignin in PTMF [17]. The FT-IR spectrum of 
TABLE 1: The FTIR spectral kinetics characteristics of PTMF before and after adsorption.

\begin{tabular}{lcccc}
\hline IR peak & Fefore adsorption & $\begin{array}{c}\text { Frequency }\left(\mathrm{cm}^{-1}\right) \\
\text { After adsorption }\end{array}$ & Differences & Assignment \\
\hline 1 & 3441 & 3425 & -16 & O-H stretching \\
2 & 1743 & 1728 & -15 & C=O stretching \\
3 & 1628 & 1659 & +31 & C=C Stretching \\
4 & 1458 & 1450 & -8 & $\mathrm{CH}_{2}$ deformation \\
5 & 1258 & 1234 & -24 & Bending modes of O-C-H, C-C-H, and C-O-H \\
6 & 1034 & 1026 & -8 & C-O stretching \\
\hline
\end{tabular}

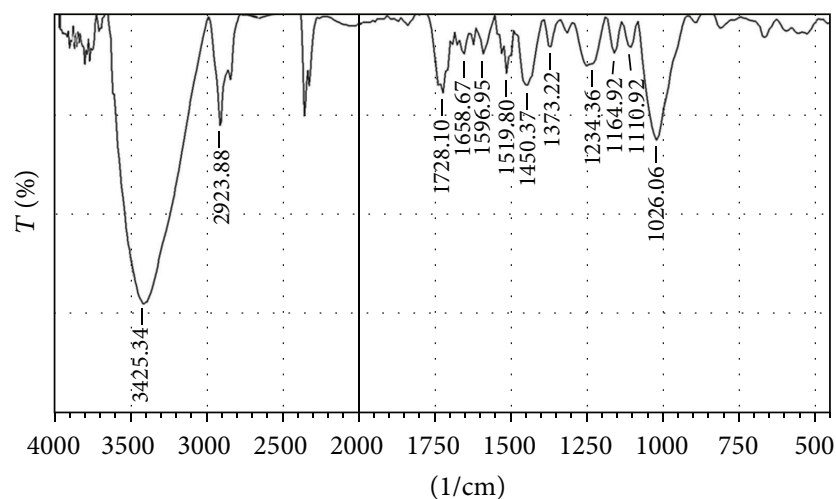

FIGURE 3: FT-IR spectra of palm tree male flower after MB adsorption.

palm tree male flower displays a number of absorption peaks, indicating the complex nature of the biosorbent (Figure 2). As seen from Figure 3 and Table 1, the spectral analysis before and after dye adsorption indicated that $-\mathrm{OH}$ group and other groups could be potential sites involved in MB adsorption.

4.2. Effect of $p H$ on Biosorption of $M B$ Dye. Effect of $p H$ on $\mathrm{MB}$ removal is shown in Figure 4. The removal of $\mathrm{MB}$ increased with the increase in $\mathrm{pH}$ of solution from 2 upto 6. A decrease of $5.87 \%$ dye removal was observed in the $\mathrm{pH}$ range of 6-9. This could be attributed to solubilization of organic groups present on the biosorbent [17]. The $\mathrm{pH}$ at the point of zero charge, $\mathrm{pH}_{\mathrm{pzc}}$ value of PTMF, was found to be 2.74 (Figure 5). At $\mathrm{pH}<\mathrm{pH}_{\mathrm{pzc}}$, the PTMF surface may get positively charged due to adsorption of the $\mathrm{H}^{+}$and a force of repulsion occurs between the dye cation and the biosorbent surface. Also, $\mathrm{H}^{+}$concentration is high at lower $\mathrm{pH}$ due to which there is a competition for vacant adsorption sites between $\mathrm{H}^{+}$and positively charged $\mathrm{MB}$ cation. This leads to lowering of the adsorption capacity.

At solution of $\mathrm{pH}>\mathrm{pH}_{\mathrm{pzc}}$, the surface of PTMF may get negatively charged due to adsorption of $\mathrm{OH}^{-}$, and the adsorption process is highly favored through electrostatic force of attraction. Similar trends were observed by various authors for $\mathrm{MB}$ adsorption on tea waste in [18], various carbon adsorbents in [9], peanut shell hull in [7], and phoenix tree leaves in [19]. At pH 6, surface of biosorbent was negatively charged to its maximum extent. Further increase in $\mathrm{pH}$

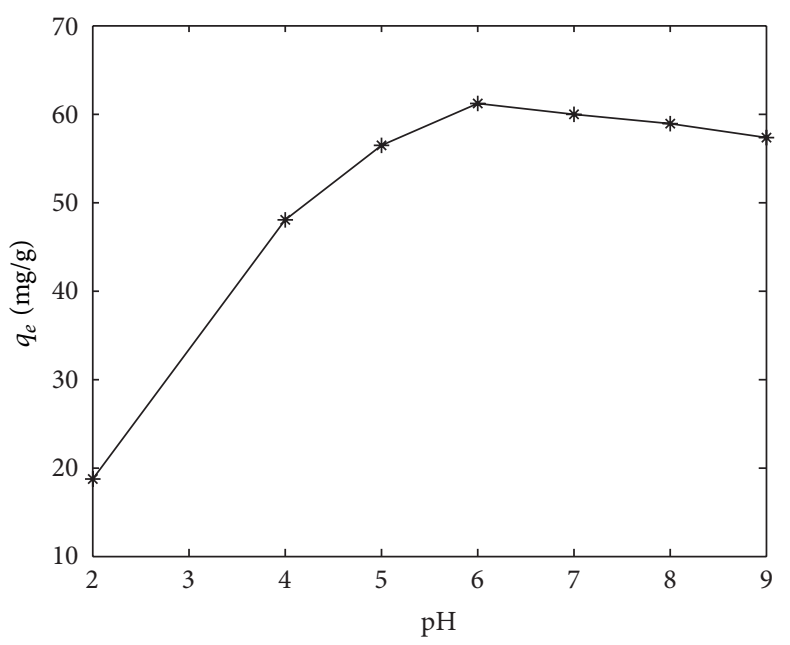

Figure 4: Effect of initial pH $\left(C_{0}: 200 \mathrm{mg} / \mathrm{L} ; V: 100 \mathrm{~mL} ; M: 0.3 \mathrm{~g}\right)$.

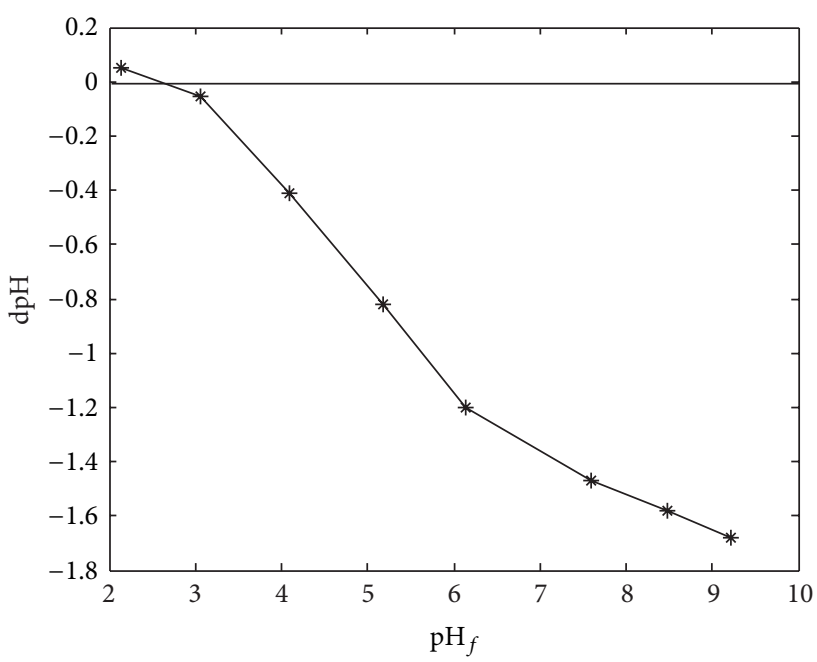

FIGURE 5: Point zero charge of palm tree male flower.

did not increase surface charge intensity as well as adsorption capability. Therefore, pH 6 was used for adsorption studies.

4.3. Effect of Biosorbent Mass. From Figure 6, it is evident that the MB sorption increases as biosorbent dose increases. The sorption rate increased from 40.75 to $91.65 \%$ at equilibrium 


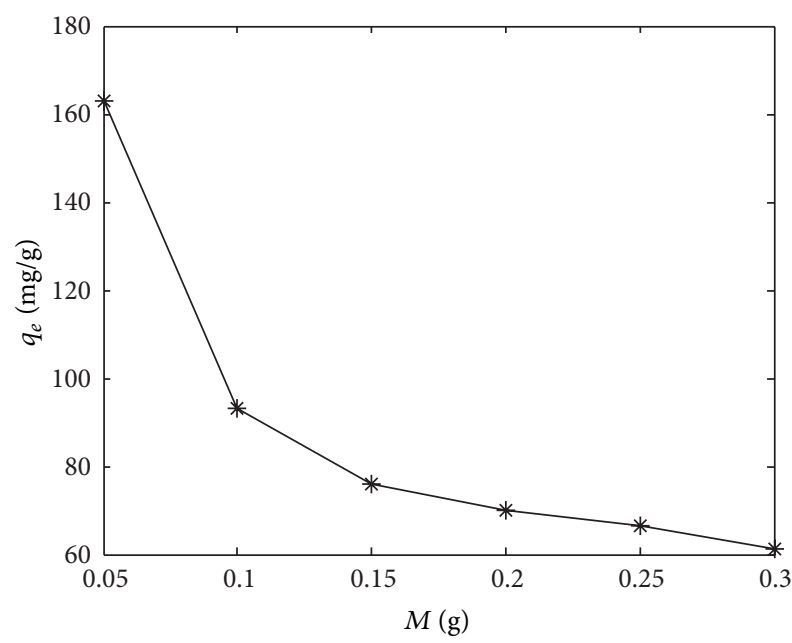

Figure 6: Effect of biosorbent mass $\left(C_{0}: 200 \mathrm{mg} / \mathrm{L} ; V: 100 \mathrm{~mL} ; \mathrm{pH}\right.$ : 6; temperature: $30^{\circ} \mathrm{C}$ ).

as PTMF dose was increased from 0.05 to $0.30 \mathrm{~g}$. This was attributed to increase in the biosorbent concentration, which increased the available surface area and the sorption sites [20]. But the sorption capacity decreased with the increase in biosorbent dosage. As the biosorbent dose was increased from 0.05 to $0.3 \mathrm{~g}$ the sorption capacity for PTMF decreased from 163 to $61.1 \mathrm{mg} / \mathrm{g}$. This may be due to overlapping of sorption sites as a result of overcrowding of biosorbent particles [21].

4.4. Effect of Biosorption Equilibrium. The adsorption isotherm indicates how the adsorbed molecules distribute between the liquid phase and the solid phase when the adsorption process reaches an equilibrium state. The analysis of the isotherm data by fitting them to different isotherm models is an important step to find suitable model that can be used for design purpose [22].

The Langmuir equation is valid for monolayer sorption onto a surface with finite number of identical sites given by the following equation:

$$
q_{e}=\frac{q_{m} b C_{e}}{\left(1+b C_{e}\right)},
$$

where $q_{m}(\mathrm{mg} / \mathrm{g})$ is the maximum amount of dye adsorbed per unit mass of biosorbent corresponding to complete coverage of the adsorption sites and $b(\mathrm{~L} / \mathrm{mg})$ is the Langmuir constant related to energy of adsorption. The linearized equation of Langmuir is represented as follows:

$$
\left(\frac{C_{e}}{q_{e}}\right)=\left(\frac{1}{b q_{m}}\right)+\left(\frac{C_{e}}{q_{m}}\right) .
$$

A plot of $C_{e} / q_{e}$ versus $C_{e}$ (Figure 7 ) yields a straight line with slope and intercept values which are used to calculate $q_{m}$ and $b$, respectively. The equilibrium data were fitted to Langmuir isotherm and the constant together with $R^{2}$ values is listed in Table 3.
TABLE 2: $R_{L}$ values at different temperature and initial MB concentrations.

\begin{tabular}{lccc}
\hline$C_{0}(\mathrm{mg} / \mathrm{L})$ & $R_{L}(T=303 \mathrm{~K})$ & $R_{L}(T=313 \mathrm{~K})$ & $R_{L}(T=323 \mathrm{~K})$ \\
\hline 50 & 0.3125 & 0.2690 & 0.2600 \\
100 & 0.1852 & 0.1560 & 0.1490 \\
150 & 0.1316 & 0.1096 & 0.1050 \\
200 & 0.1020 & 0.0845 & 0.0800 \\
250 & 0.0833 & 0.0687 & 0.0657 \\
300 & 0.0704 & 0.0579 & 0.0553 \\
\hline
\end{tabular}

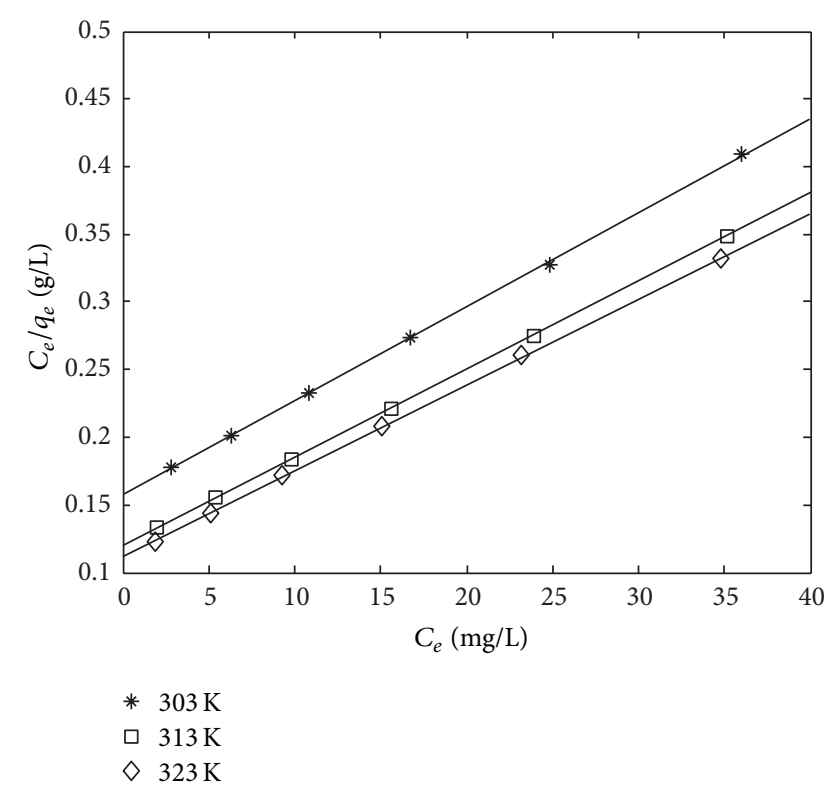

FIgURE 7: Linearized Langmuir isotherm at different temperatures (M: $0.3 \mathrm{~g} ; \mathrm{pH}$ : 6; agitation rpm: 150).

The essential characteristics of the Langmuir isotherm can be expressed in terms of a dimensionless constant separation factor $R_{L}$ that is given by the following equation [23]:

$$
R_{L}=\frac{1}{\left(1+b C_{0}\right)}
$$

where $C_{0}(\mathrm{mg} / \mathrm{L})$ is the highest initial concentration of adsorbate. The value of $R_{L}$ indicates the shape of the isotherm to be either unfavorable $\left(R_{L}>1\right)$, linear $\left(R_{L}=1\right)$, favorable $\left(0<R_{L}<1\right)$, or irreversible $\left(R_{L}=0\right)$. For the adsorption of MB onto PTMF, the $R_{L}$ values obtained are shown in Table 2 and Figure 8. The $R_{L}$ values for adsorption of $\mathrm{MB}$ onto PTMF are in the range of 0.07 to 0.3125 at $303 \mathrm{~K}, 0.058$ to 0.27 at $313 \mathrm{~K}$, and 0.055 to 0.26 at $323 \mathrm{~K}$, indicating that the adsorption is a favorable process.

The Fruendlich isotherm [24] is an empirical equation assuming that the adsorption process takes place on heterogeneous surfaces and the adsorption capacity is related to the concentration of $\mathrm{MB}$ dye at equilibrium by

$$
q_{e}=K_{F} C_{e}^{1 / n}
$$


TABle 3: Langmuir, Fruendlich, Tempkin, and generalized isotherm constants for MB onto PTMF at different temperatures.

\begin{tabular}{|c|c|c|c|c|c|c|c|c|c|c|c|c|c|}
\hline \multirow{2}{*}{$T, \mathrm{~K}$} & \multicolumn{4}{|c|}{ Langmuir isotherm } & \multicolumn{3}{|c|}{ Fruendlich isotherm } & \multicolumn{3}{|c|}{ Tempkin isotherm } & \multicolumn{3}{|c|}{ Generalized isotherm } \\
\hline & $q_{m}(\mathrm{mg} / \mathrm{g})$ & $b(\mathrm{~L} / \mathrm{mg})$ & $b(\mathrm{~L} / \mathrm{mol})$ & $R^{2}$ & $\begin{array}{c}K_{F} \\
(\mathrm{mg} / \mathrm{g}) /(\mathrm{mg} / \mathrm{L})^{1 / n}\end{array}$ & $n$ & $R^{2}$ & $B$ & $A(\mathrm{~L} / \mathrm{mg})$ & $R^{2}$ & $K(\mathrm{mg} / \mathrm{L})$ & $n$ & $R^{2}$ \\
\hline 303 & 143.6 & 0.0440 & 14073.9 & 0.99995 & 8.51 & 1.47 & 0.9857 & 28.75 & 0.525 & 0.9839 & 22.87 & 1.000 & 0.9999 \\
\hline 313 & 153.9 & 0.0514 & 17323.6 & 1.00000 & 10.53 & 1.49 & 0.9822 & 30.48 & 0.683 & 0.9812 & 18.47 & 0.990 & 1.0000 \\
\hline 323 & 157.3 & 0.0569 & 18200.0 & 0.99981 & 11.28 & 1.52 & 0.9829 & 31.21 & 0.716 & 0.9802 & 17.46 & 0.997 & 0.9999 \\
\hline
\end{tabular}

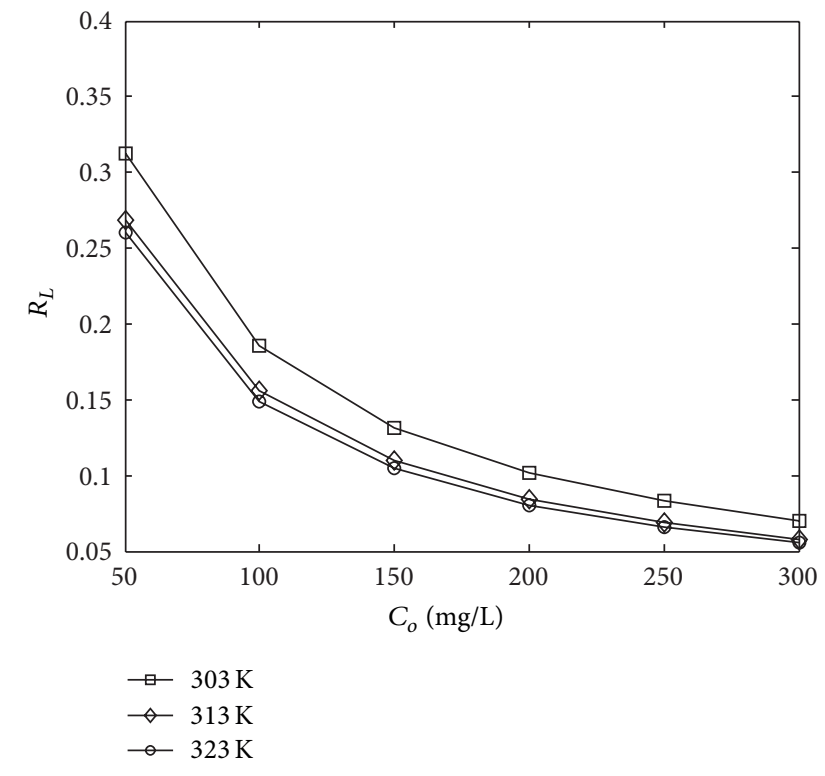

Figure 8: Separation factor $R_{L}$ for MB onto palm male flower.

where $K_{F}\left(\mathrm{mg} / \mathrm{g}(\mathrm{L} / \mathrm{mg})^{1 / n}\right)$ is roughly an indicator of the adsorption capacity and $1 / n$ is the adsorption intensity. The magnitude of the exponent, $1 / n$, gives the indication of the favorability of adsorption. The linear form of Freundlich's expression can be obtained by taking the logarithm of (see (16)) given by

$$
\ln q_{e}=\ln K_{F}+\left(\frac{1}{n}\right) \ln C_{e}
$$

The plot of $\ln q_{e}$ against $\ln C_{e}$ (Figure 9) yields a straight line with slope and intercept values which are used to calculate $n$ and $K_{F}$, respectively. The equilibrium data were fitted to Freundlich isotherm and the constants together with $R^{2}$ values are listed in Table 3. From the table, values of $n$ varies from 1.47 to 1.52 when the temperature vary from 303 to $323 \mathrm{~K}$ indicating favorable adsorption system.

Tempkin and Pyzhev [25] studied the heat of adsorption and adsorbent-adsorbate interaction on the surfaces. The Tempkin isotherm is given by

$$
q_{e}=\left(\frac{R T}{b}\right) \ln \left(A C_{e}\right)
$$

or

$$
q_{e}=B \ln \left(A C_{e}\right)
$$

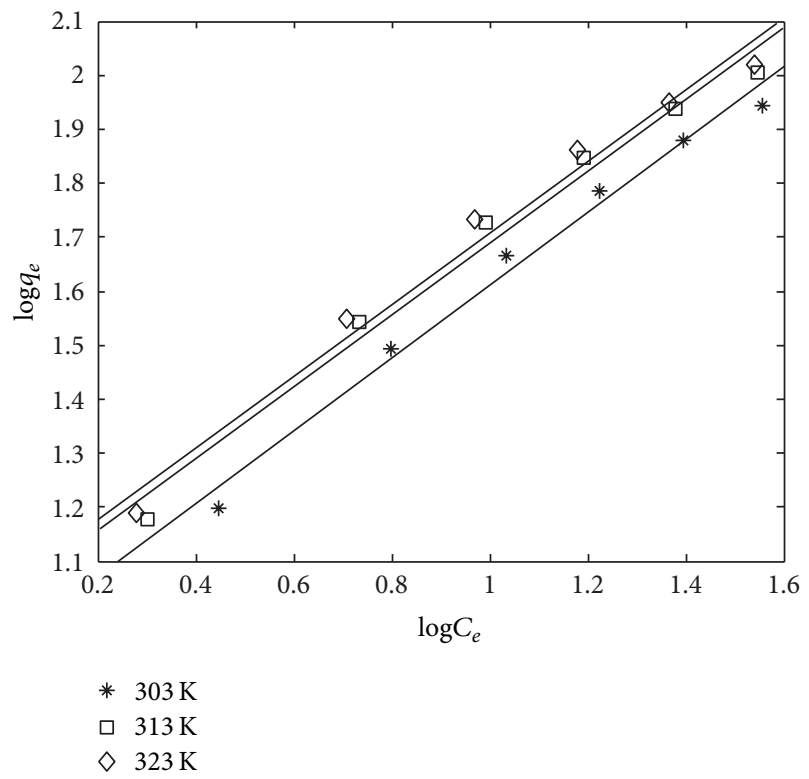

FIGURE 9: Linearized Freundlich isotherm at different temperatures (M: $0.3 \mathrm{~g}$; pH: 6; agitation rpm: 150).

where $B=(R T / b), T(\mathrm{~K})$ is the absolute temperature, and $R$ $(8.314 \mathrm{KJ} / \mathrm{Kmol} \mathrm{K})$ is the universal gas constant. $A(\mathrm{~L} / \mathrm{mg})$ is equilibrium binding constant and $b(\mathrm{KJ} / \mathrm{mol})$ is the variation of adsorption energy. A linear form of (19) can be expressed by

$$
q_{e}=B \ln A+B \ln C_{e} .
$$

A plot of $q_{e}$ versus $\ln C_{e}$ (Figure 10) enables one to determine the constants $A$ and $B$. The values of Tempkin constant and correlation coefficient, $R^{2}$, are listed in Table 3 . The $R^{2}$ values are lower than Freundlich and Langmuir values.

Generalized adsorption isotherm in [26] has been used in the following form:

$$
q_{e}=\frac{q_{\max } C_{e}^{n}}{\left(K+C_{e}^{n}\right)}
$$

A linear form of this equation is given by

$$
\ln \left(\left(\frac{q_{\max }}{q_{e}}\right)-1\right)=\ln K-n \ln C_{e},
$$

where $K(\mathrm{mg} / \mathrm{L})$ is saturation constant, $n$ is the cooperative binding constant, $q_{\max }(\mathrm{mg} / \mathrm{g})$ is the maximum adsorption 


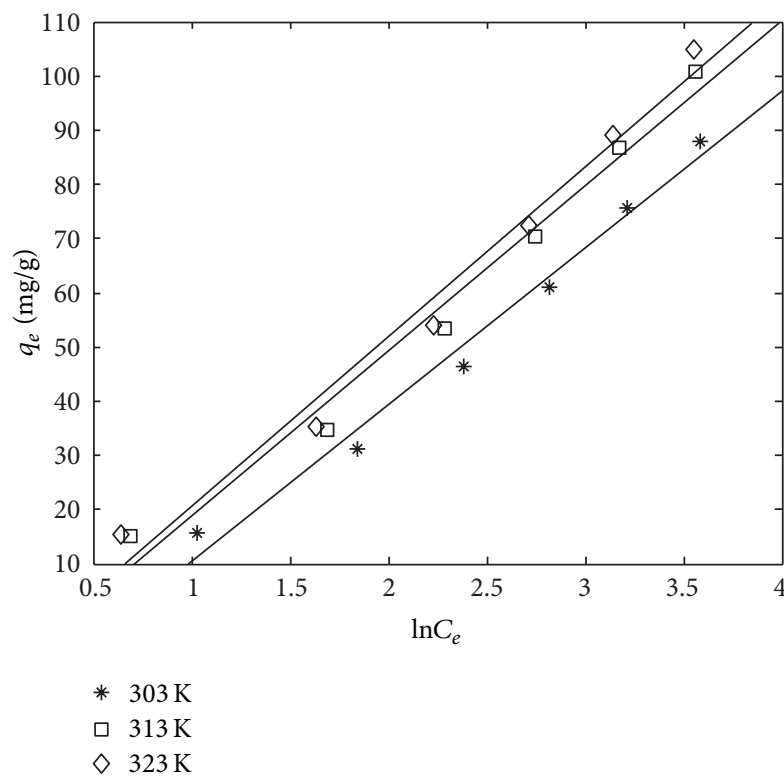

FIgURE 10: Linearized Tempkin isotherm at different temperatures ( $M$ : $0.3 \mathrm{~g} ; \mathrm{pH}$ : 6; agitation rpm: 150).

capacity of biosorbent, and $q_{e}(\mathrm{mg} / \mathrm{g})$ and $C_{e}(\mathrm{mg} / \mathrm{L})$ are the equilibrium dye concentration in the solid and liquid phase, respectively. A plot of equilibrium data in the form of $\ln \left(\left(q_{\max } / q_{e}\right)-1\right)$ versus $\ln C_{e}$ (Figure 11) gives constant $K$ and $n$. The $q_{\max }$ values were taken from Langmuir isotherm. The slope and the intercept of the best fit line are presented in Table 3. The values of correlation coefficient are much higher than Fruendlich and Tempkin isotherm values.

As shown in Table 3, the Langmuir equation represents the biosorption process very well; the $R^{2}$ values were higher than 0.997 , indicating a very good mathematical fit. The fact that Langmuir isotherm fits the experimental data very well may be due to homogenous distribution of active sites on the PTMF surface, since the Langmuir equation assumes that the surface is homogenous. A comparison between the adsorption capacities of PTMF and other adsorbents is presented in Table 4. When comparing our results for PTMF with the results of others, it can be concluded that the PTMF has adsorbed MB dye as effective as other adsorbents listed.

4.5. Biosorption Kinetics. Figure 12 shows the effect of initial dye concentration on the rate of MB dye uptake onto PTMF. It is evident that the amount of dye adsorbed gets increased with the increasing dye concentration and contact time. It is also observed that the rate of MB uptake was found to be very rapid for the initial contact period of 45 to $60 \mathrm{~min}$ and thereafter the dye uptake rate slowed down and finally reached saturation. The higher sorption rate at the initial period may be due to more number of vacant sites available at the initial stages; as a result there exist increased concentration gradients between $\mathrm{MB}$ in solution and the $\mathrm{MB}$ in the PTMF surface. As time progresses, this concentration is reduced due to accumulation of $\mathrm{MB}$ particles in the vacant sites, leading to a decrease in sorption rate at a later stage.

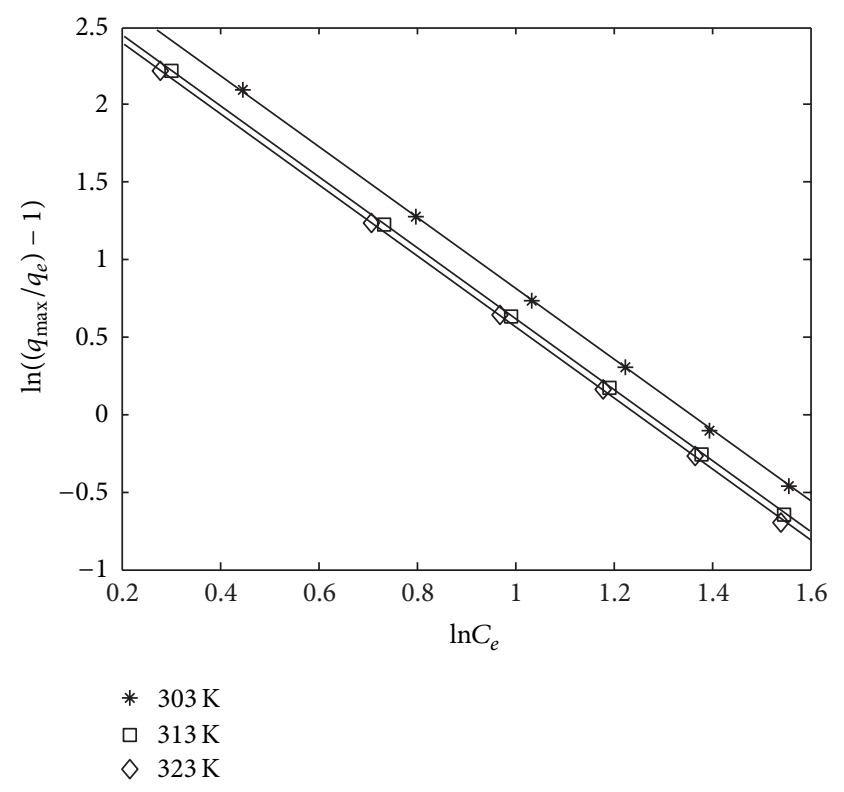

FIGURE 11: Linearized generalized isotherm at different temperatures (M: $0.3 \mathrm{~g} ; \mathrm{pH}$ : 6; agitation rpm: 150).

TABLE 4: Maximum sorption capacity of different sorbents in MB.

\begin{tabular}{lcc}
\hline Sorbent material & $\begin{array}{c}\text { Maximum sorption } \\
\text { capacity, } q_{m}(\mathrm{mg} / \mathrm{g})\end{array}$ & Reference \\
\hline Teak wood bark & 915 & {$[27]$} \\
Spent tea leaves & 300 & {$[28]$} \\
Untreated guava leaves & 295 & {$[10]$} \\
Gulmohar plant leaf powder & $120-252.7$ & {$[29]$} \\
Castor seed shell & 158.73 & {$[8]$} \\
Palm tree male flower (PTMF) & $143.6-157.31$ & This study \\
Mango seed kernel & $142.9-153.85$ & {$[30]$} \\
Chemically treated guava & 133.33 & {$[31]$} \\
leaves & 95.2 & {$[1]$} \\
Wood apple shell & 76.9 & {$[32]$} \\
Hazelnut shell & 40.6 & {$[4]$} \\
Rice husk & 20.3 & {$[33]$} \\
Natural chaff & 19.61 & {$[3]$} \\
Neem leaf & 18.6 & {$[34]$} \\
Orange peels & & \\
\hline
\end{tabular}

The rate constant of adsorption is determined from the linear pseudofirst-order rate expression given by Lagergren in [35] in the following form:

$$
\log \left(q_{e}-q\right)=\log q_{e}-K_{1}\left(\frac{t}{2.303}\right),
$$

where $q_{e}$ and $q$ are amounts of dye adsorbed (mg/g) at equilibrium and at time $t(\mathrm{~min})$, respectively, and $K_{1}\left(\mathrm{~min}^{-1}\right)$ is the rate constant of adsorption. Values of $K_{1}$ were calculated from the plot of $\log \left(q_{e}-q\right)$ versus $t$ (Figure 13). The calculated values of $q_{e}$ and $K_{1}$ and the corresponding linear regression 
TABLE 5: Kinetic values calculated for MB adsorption on PTMF ( $\mathrm{pH}-6$, temperature $=303 \mathrm{~K}$ ).

\begin{tabular}{lccccccccc}
\hline \multicolumn{4}{c}{ First-order kinetic } & \multicolumn{3}{c}{ Second-order kinetic } \\
$\begin{array}{l}\text { Conc. } \\
(\mathrm{mg} / \mathrm{L})\end{array}$ & $\begin{array}{c}q_{e}(\mathrm{mg} / \mathrm{g}) \\
\text { experiment }\end{array}$ & $\begin{array}{c}K_{1} \\
\left(\mathrm{~min}^{-1}\right)\end{array}$ & $\begin{array}{c}q_{e}(\mathrm{mg} / \mathrm{g}) \\
\text { calculated }\end{array}$ & $R^{2}$ & $\begin{array}{c}q_{e}(\mathrm{mg} / \mathrm{g}) \\
\text { calculated }\end{array}$ & $\begin{array}{c}K_{2} \times 10^{3} \\
(\mathrm{~g} / \mathrm{mg} \cdot \mathrm{min})\end{array}$ & $R^{2}$ & $h(\mathrm{mg} / \mathrm{g} \cdot \mathrm{min})$ & $t_{1 / 2}$ \\
$(\mathrm{~min})$
\end{tabular}

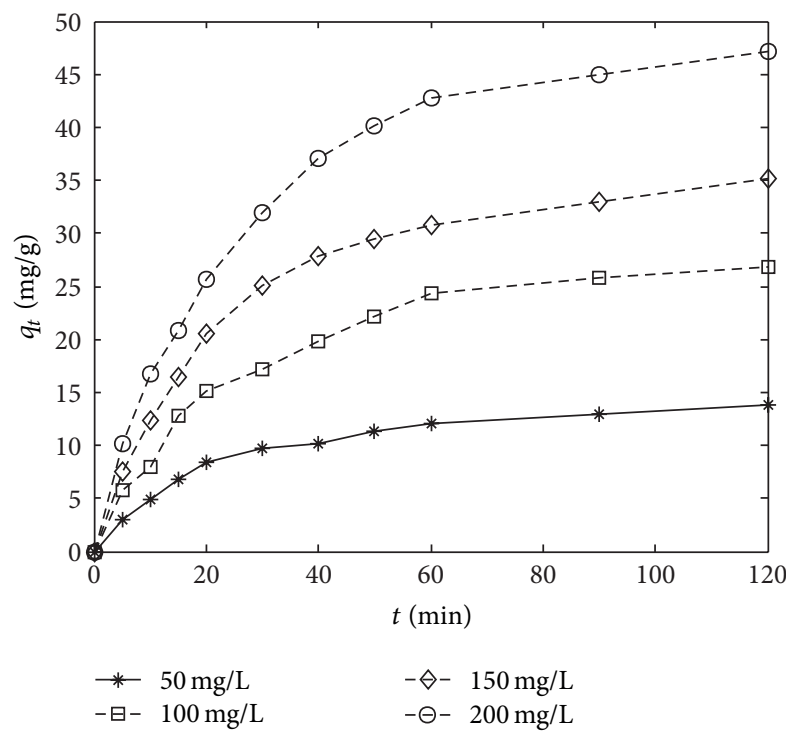

FIGURE 12: Biosorption kinetics for MB onto PTMF ( $M: 3 \mathrm{~g} ; V: 1 \mathrm{~L}$; pH: 6; agitation rpm: 150).

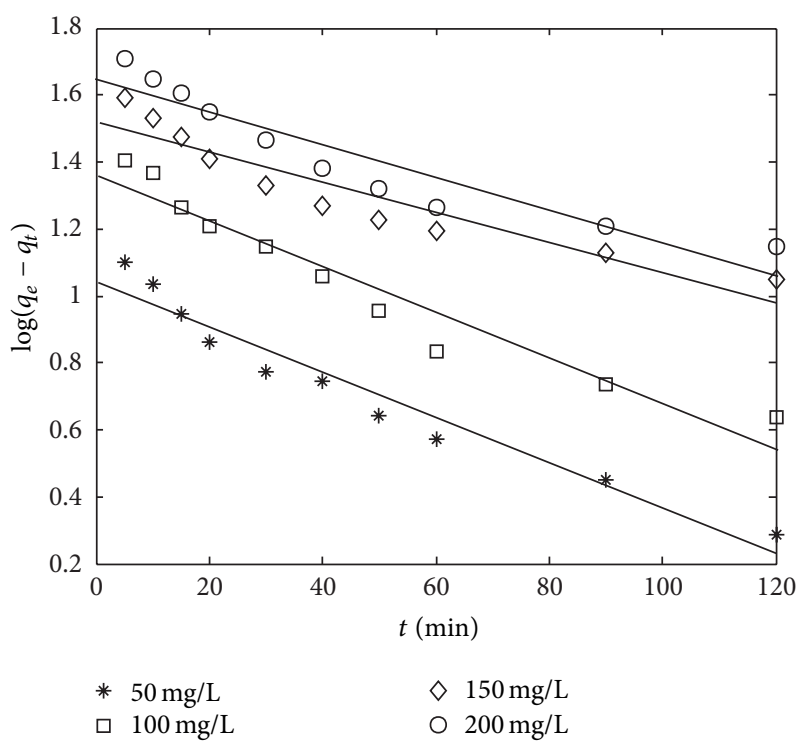

FIGURE 13: Lagergren pseudofirst-order kinetics for MB onto PTMF ( $V: 1 \mathrm{~L}, \mathrm{pH}: 6$; agitation rpm: 150).

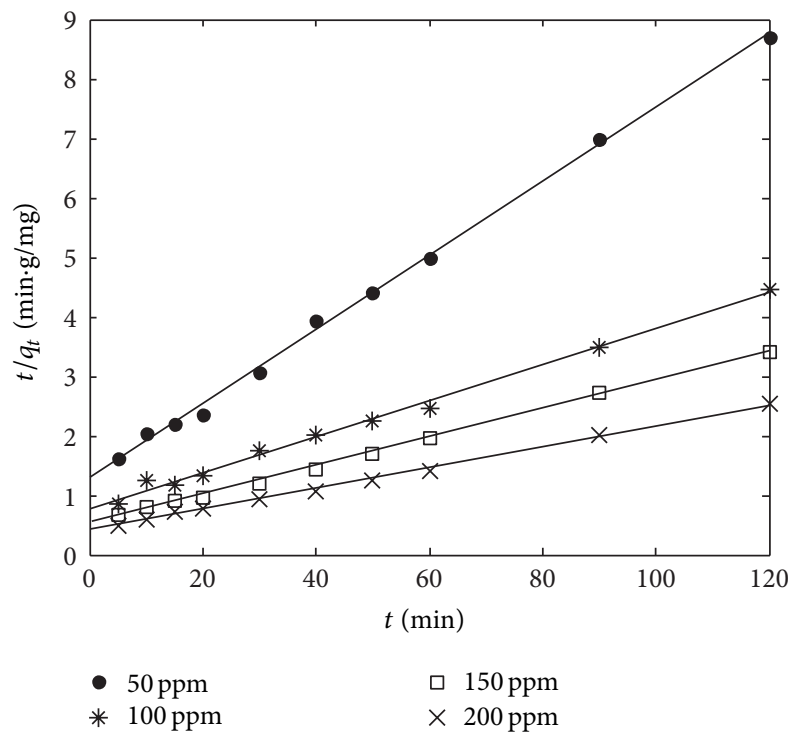

FIgURE 14: Ho pseudosecond-order kinetics for MB onto PTMF ( $V$ : $1 \mathrm{~L}, \mathrm{pH}$ : 6; agitation rpm: 150).

correlation coefficient $\left(R^{2}\right)$ are shown in Table 5. The $R^{2}$ values show that the pseudofirst-order model is not good in predicting the kinetics of $\mathrm{MB}$ adsorption onto PTMF.

The kinetic data were further analyzed using Ho's pseudosecond-order kinetics represented by in [36]

$$
\frac{t}{q}=\left(\frac{1}{K_{2} q_{e}^{2}}\right)+\frac{t}{q_{e}},
$$

where $K_{2}(\mathrm{~g} / \mathrm{mg} \cdot \mathrm{min})$ is the rate constant of pseudosecondorder adsorption. If the second-order kinetics is applicable, then the plot of $t / q$ versus $t$ should be a linear relationship. The initial adsorption rate, $h(\mathrm{mg} / \mathrm{g} \cdot \mathrm{min})$, as $t \rightarrow 0$ can be defined as $h=K_{2} q_{e}^{2}$. The initial adsorption rate $(h)$, the equilibrium adsorption capacity $\left(q_{e}\right)$, and the second-order constant $\left(K_{2}\right)$ can be determined experimentally from the slope and intercept of plot $t / q$ versus $t$ (Figure 14) and the values are shown in Table 5. Calculated correlation coefficient $\left(R^{2}\right)$ is closer to unity and its equilibrium adsorption capacity, $q_{e}$ (calculated), is consistent with experimental data. These facts suggest that the pseudosecond-order kinetic mechanism is predominant and that the overall rate of dye adsorption process appears to be controlled by chemisorption process 
TABLE 6: Intraparticle diffusion constants for different initial MB concentration.

\begin{tabular}{lccccc}
\hline$C_{0}(\mathrm{mg} / \mathrm{L})$ & $K_{i, 1}\left(\mathrm{mg} / \mathrm{g} \cdot \mathrm{min}^{0.5}\right)$ & $I_{1}$ & $R^{2}$ & $K_{i, 2}\left(\mathrm{mg} / \mathrm{g} \cdot \mathrm{min}^{0.5}\right)$ & $I_{2}$ \\
\hline 50 & 2.155 & -1.664 & 0.9837 & 0.750 & 5.78 \\
100 & 3.361 & -1.297 & 0.9828 & 0.780 & 0.966 \\
150 & 5.139 & -3.580 & 0.9897 & 1.514 & 0.999 \\
200 & 6.022 & -2.183 & 0.9960 & 1.336 & 0.991 \\
\hline
\end{tabular}

[4]. Similar phenomena have been observed in the sorption of $\mathrm{MB}$ onto rice husk in [4], removal of $\mathrm{MB}$ from perlite in [37, 38], removal of $\mathrm{MB}$ from guava leaf powder in [10], adsorption of $\mathrm{MB}$ onto wheat shell in [5], activated carbon prepared from rattan sawdust in [39], and spent tea leaves in [28].

The half adsorption time of dye $t_{1 / 2}$ that is the time required for PTMF to uptake half the amount adsorbed at equilibrium is often considered as a measure of rate of adsorption and for the second-order process is given by the following relation $[40]$ :

$$
t_{1 / 2}=\frac{1}{k_{2} q_{e}} .
$$

The determined values for $t_{1 / 2}$ for the tested parameters are given in Table 5.

4.6. Intraparticle Diffusion. The models mentioned above in adsorption kinetics cannot identify a diffusion mechanism. The adsorbate species are most probably transported from the bulk of the solution into the solid phase through an intraparticle diffusion process, which is often the rate limiting step in many adsorption processes. The possibility of intraparticle diffusion model based on Weber and Morris [40] was also tested. It is an empirically found functional relationship common to most adsorption processes, where uptake varies almost proportional with $t^{1 / 2}$ rather than with the contact time $t$. According to this theory,

$$
q_{t}=K_{i} t^{1 / 2}+C,
$$

where $K_{i}\left(\mathrm{mg} / \mathrm{g} \cdot \mathrm{min}^{1 / 2}\right)$, the intraparticle diffusion rate constant, is obtained from the slope of straight line of $q_{t}$ versus $t^{1 / 2}$ (Figure 15). The values of $K_{i}, C$, and correlation coefficient $\left(R^{2}\right)$ obtained from plots are given in Table 6. The intercept $C$ gives an idea about the thickness of boundary layer that is the larger the intercept, the greater the boundary layer effect. If intraparticle diffusion occurs, then plot of $q_{t}$ versus $t^{1 / 2}$ will be linear and if the plot passes through the origin, then the rate limiting process is only due to intraparticle diffusion. Otherwise some other mechanisms along with intraparticle diffusion are also involved [29]. As it is shown Figure 15, the plot of $q_{t}$ versus $t^{1 / 2}$ consists of two linear sections with different slopes. A similar multilinearity has been observed with MB adsorption on sepolite in [29] cyclodextrin in [41]. The multilinearity indicates that two or more steps occur in the sorption process. The two linear sections in plot were evaluated separately using (26) and the model parameters are listed in Table 6.

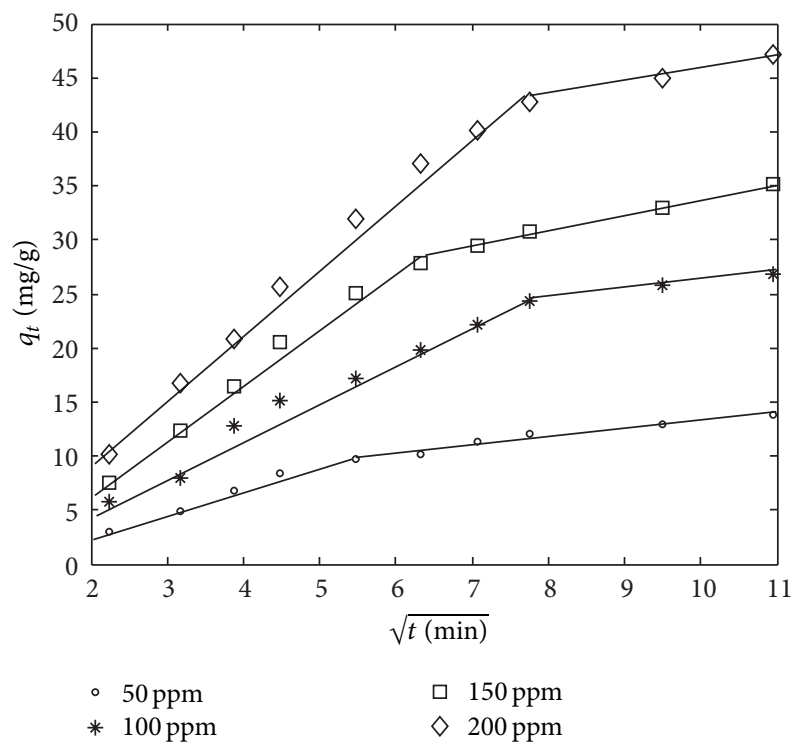

FIGURE 15: Intraparticle diffusion for different initial MB concentrations.

4.7. Estimation of Thermodynamics Parameters. The free energy of adsorption, $\Delta G^{\circ}$, can be related to equilibrium constant $K(\mathrm{~L} / \mathrm{mol})$ corresponding to the reciprocal of the Langmuir constant, by the following [42]:

$$
\Delta G^{\circ}=-R T \ln b,
$$

where $R(8.314 \mathrm{~J} / \mathrm{mol} \mathrm{K})$ is the universal gas constant and $T$ $(\mathrm{K})$ is absolute temperature. Also the enthalpy $\left(\Delta H^{\circ}\right)$ and entropy $\left(\Delta S^{\circ}\right)$ changes can be estimated by the following equation:

$$
\ln b=\left(\frac{\Delta S^{\circ}}{R}\right)-\left(\frac{\Delta H^{\circ}}{R T}\right) .
$$

Thus a plot of $\ln b$ versus $1 / T$ (Figure 16) should be a straight line. $\Delta H^{\circ}$ and $\Delta S^{\circ}$ values were obtained from the slope and intercept of the plot, respectively. $\Delta G^{\circ}, \Delta H^{\circ}$, and $\Delta S^{\circ}$ obtained from (27) and (28) are given in Table 7. The equilibrium constants obtained from Langmuir model at 303, 313, and $323 \mathrm{~K}$ were used to determine Gibbs free energy changes. The plot of $\ln b$ versus $1 / T$ had a very good linearity with regression coefficient of 0.9972 . The $b$ value increased with increasing temperature which resulted in a shift of adsorption to the right. The Gibbs free energy values for adsorption process were obtained as $-24.06,-25.4$, and $-26.34 \mathrm{KJ} / \mathrm{mol}$ for temperatures of 303,313 , and $323 \mathrm{~K}$, respectively. 


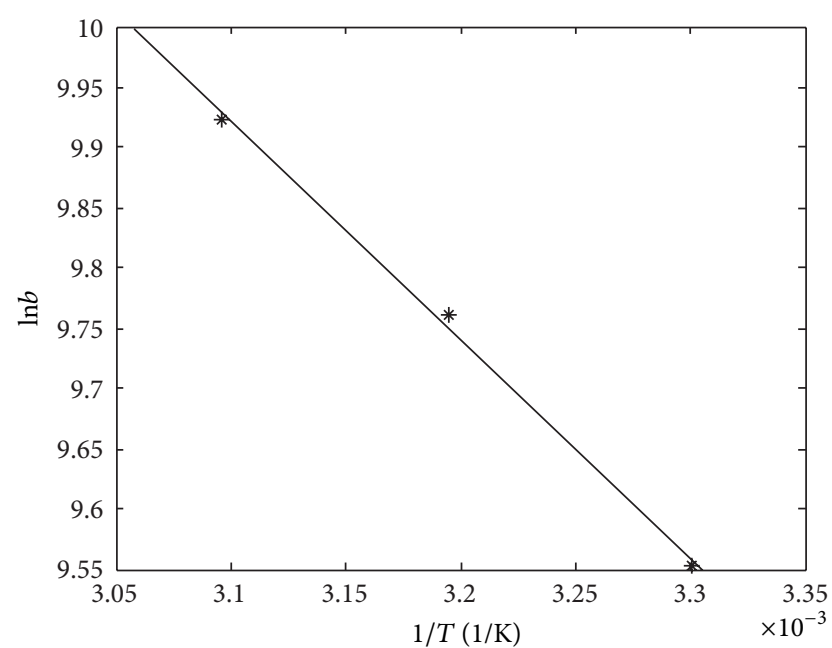

Figure 16: Plot of $\ln b$ versus $1 / T$ for biosorption of MB onto PTMF.

TABLE 7: Values of thermodynamic parameter for the adsorption of MB onto PTMF.

\begin{tabular}{lcccc}
\hline$T(\mathrm{~K})$ & $\Delta G^{\circ}(\mathrm{KJ} / \mathrm{mol})$ & $\Delta H^{\circ}(\mathrm{KJ} / \mathrm{mol})$ & $\Delta S^{\circ}(\mathrm{KJ} / \mathrm{mol} \mathrm{K})$ & $R^{2}$ \\
\hline 303 & -24.06 & & & \\
313 & -25.40 & 15.06 & 0.129 & 0.9972 \\
323 & -26.34 & & & \\
\hline
\end{tabular}

The negative value of $\Delta G^{\circ}$ indicates the spontaneous nature of MB adsorption onto PTMF. According to (28), the enthalpy and entropy values in the range of 303-323 K were obtained as $15.06 \mathrm{KJ} / \mathrm{mol}$ and $0.129 \mathrm{KJ} / \mathrm{mol} \mathrm{K}$, respectively. The positive value of $\Delta H^{\circ}$ indicates that the adsorption is an endothermic process. The increase in temperature would increase the rate of diffusion of the adsorbate molecules across the external boundary layer and also in the internal pores of biosorbent particles, owing to the decrease in viscosity of solution [43]. The positive value of $\Delta S^{\circ}$ showed the increase in randomness at the solid-solution interface during adsorption.

4.8. Mathematical Model. The equilibrium data were approximated by Langmuir isotherm. The linear regression analysis was employed to determine isotherm constants $q_{m}$ and $K_{L}$. The estimated isotherm constants at temperature of $30^{\circ} \mathrm{C}$ are $q_{m}=145 \mathrm{mg} / \mathrm{g}$ and $K_{L}=0.044$ and correlation coefficient is 0.9999 which indicates a satisfactory description of equilibrium data by isotherm model. Figures 17, 18, 19, and 20 show the experimental decay-time profile of $\mathrm{MB}$ adsorption onto PTMF at different initial solute concentration. As shown, the mentioned model describes well the experimental data. The correlation coefficients for all experiments were computed and reported in Table 8. All correlation coefficient are in excess of 0.99 , indicating satisfactory fit of model prediction and experimental data. The estimated values of $D_{L}$ and $K_{c}$ are $9 \times 10^{-10} \mathrm{~m}^{2} / \mathrm{s}$ and $1.2 \times 10^{-5} \mathrm{~m} / \mathrm{s}$, respectively.

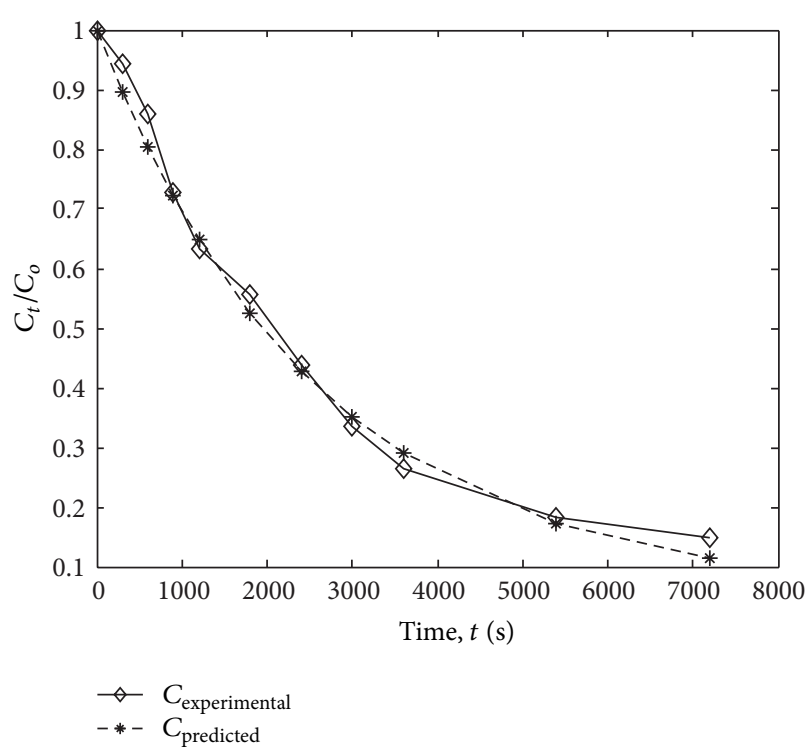

FIGURE 17: Variation of dimensionless bulk concentration of MB with time for initial bulk concentration of $50 \mathrm{mg} / \mathrm{L}$.

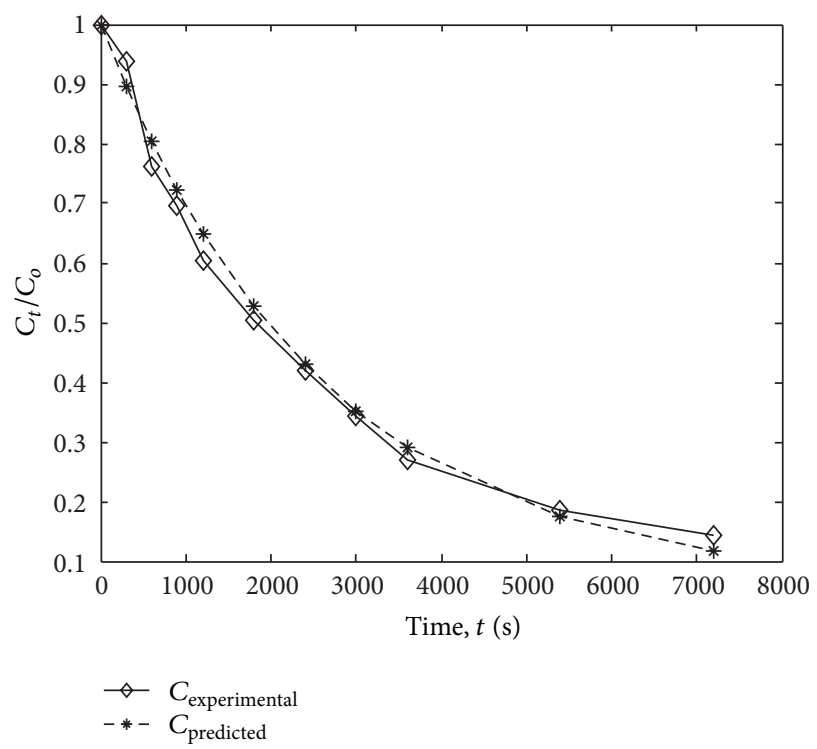

FIGURE 18: Variation of dimensionless bulk concentration of MB with time for initial bulk concentration of $100 \mathrm{mg} / \mathrm{L}$.

\section{Conclusions}

The present study shows that PTMF, a plant waste material, can be used as a potential biosorbent for removal of $\mathrm{MB}$ from aqueous solution. The amount of dye adsorbed was found to vary with biosorbent dosage, initial dye concentration, and $\mathrm{pH}$ and temperature. The amount of dye uptake $(\mathrm{mg} / \mathrm{g})$ was found to increase with temperature and initial dye concentration but decreased with increase in biosorbent dosage. The rate of adsorption was found to conform to pseudosecond-order kinetics with a very good correlation coefficient. Equilibrium data fitted very well with 


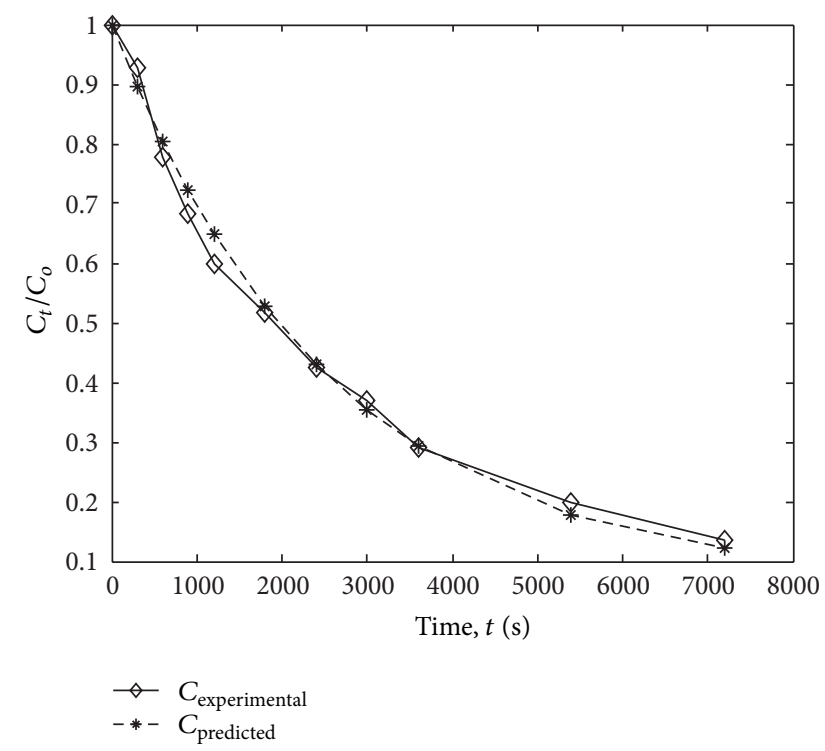

FIGURE 19: Variation of dimensionless bulk concentration of MB with time for initial bulk concentration of $150 \mathrm{mg} / \mathrm{L}$.

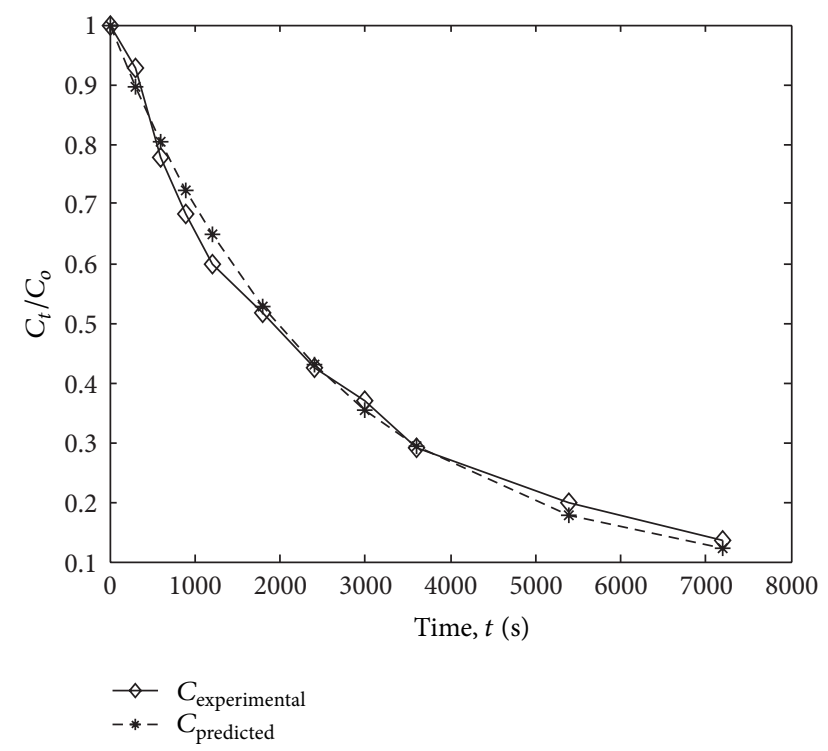

Figure 20: Variation of dimensionless bulk concentration of MB with time for initial bulk concentration of $200 \mathrm{mg} / \mathrm{L}$.

the Langmuir isotherm equation and generalized isotherm confirming the monolayer adsorption capacity of $\mathrm{MB}$ onto PTMF with a monolayer adsorption capacity of $157.3 \mathrm{mg} / \mathrm{g}$ at $323 \mathrm{~K}$. The dimensionless separation factor $\left(R_{L}\right)$ showed that PTMF can be used for removal of MB from aqueous solutions. The thermodynamic parameters indicate spontaneous and endothermic process. The mathematical model derived gave a satisfactory fit of model prediction and experimental data thereby indicating that the adsorption is only taking place on the surface of the PTMF with negligible intraparticle diffusion. PTMF, an inexpensive and abundantly available
TABLE 8: Values of liquid phase diffusivity and mass transfer coefficient obtained by model.

\begin{tabular}{lccc}
\hline Conc. $(\mathrm{mg} / \mathrm{L})$ & $D_{L} \times 10^{10}\left(\mathrm{~m}^{2} / \mathrm{s}\right)$ & $K_{c} \times 10^{5}(\mathrm{~m} / \mathrm{s})$ & $R^{2}$ \\
\hline 50 & 9.0 & 1.2 & 0.9904 \\
100 & 9.0 & 1.2 & 0.9906 \\
150 & 9.0 & 1.2 & 0.9916 \\
200 & 9.0 & 1.2 & 0.9942 \\
\hline
\end{tabular}

material, can be used as an alternative for more costly adsorbents used for dye removal in waste water treatment.

The disposal of biosorbent loaded with dye must be evaluated so as to ensure environmentally safe conditions. The following disposal options may be considered: (i) burning after drying and the heat used for steam generation; (ii) use of composite materials; (iii) composting process of biodegradable wastes; (iv) regeneration by treatment with acid or organic solvent solution and reuse in other cycle of biosorption [44].

\section{Greek Symbol}

$\Phi$ : solid loading ( $\mathrm{kg} / \mathrm{m} 3$ of liquid).

\section{Conflict of Interests}

The authors declare that there is no conflict of interests regarding the publication of this paper.

\section{References}

[1] R. Malarvizhi and N. Sulochana, "Sorption isotherm and kinetic studies of methylene blue uptake onto activated carbon prepared from wood apple shell," Journal of Environmental Protection Science, vol. 2, pp. 40-46, 2008.

[2] G. Crini, "Non-conventional low-cost adsorbents for dye removal: a review," Bioresource Technology, vol. 97, no. 9, pp. 1061-1085, 2006.

[3] K. G. Bhattacharya and A. Sharma, "Kinetics and thermodynamics of methylene blue adsorption on Neem (Azadirachta indica) leaf powder," Dyes and Pigments, vol. 65, no. 1, pp. 5159, 2005.

[4] V. Vadivelan and K. Vasanth Kumar, "Equilibrium, kinetics, mechanism, and process design for the sorption of methylene blue onto rice husk," Journal of Colloid and Interface Science, vol. 286, no. 1, pp. 90-100, 2005.

[5] Y. Bulut and H. Aydin, "A kinetics and thermodynamics study of methylene blue adsorption on wheat shells," Desalination, vol. 194, no. 1-3, pp. 259-267, 2006.

[6] S. J. Allen and B. Koumanova, "Decolorisation of water/wastewater using adsorption (review)," Journal of the University of Chemical Technology and Metallurgy, vol. 40, pp. 175-192, 2005.

[7] D. Özer, G. Dursun, and A. Özer, "Methylene blue adsorption from aqueous solution by dehydrated peanut hull," Journal of Hazardous Materials, vol. 144, no. 1-2, pp. 171-179, 2007.

[8] N. A. Oladoja, C. O. Aboluwoye, Y. B. Oladimeji, A. O. Ashogbon, and I. O. Otemuyiwa, "Studies on castor seed shell 
as a sorbent in basic dye contaminated wastewater remediation," Desalination, vol. 227, no. 1-3, pp. 190-203, 2008.

[9] N. Kannan and M. M. Sundaram, "Kinetics and mechanism of removal of methylene blue by adsorption on various carbons-a comparative study," Dyes and Pigments, vol. 51, no. 1, pp. 25-40, 2001.

[10] V. Ponnusami, S. Vikram, and S. N. Srivastava, "Guava (Psidium guajava) leaf powder: novel adsorbent for removal of methylene blue from aqueous solutions," Journal of Hazardous Materials, vol. 152, no. 1, pp. 276-286, 2008.

[11] R. Han, Y. Wang, X. Zhao et al., "Adsorption of methylene blue by phoenix tree leaf powder in a fixed-bed column: experiments and prediction of breakthrough curves," Desalination, vol. 245, no. 1-3, pp. 284-297, 2009.

[12] S. Patil, S. Renukdas, and N. Patel, "Removal of methylene blue, a basic dye from aqueous solutions by adsorption using teak tree (Tectona grandis) bark powder," International Journal of Environmental Sciences, vol. 1, no. 5, pp. 711-725, 2011.

[13] V. Ponnusami, V. Gunasekar, and S. N. Srivastava, "Kinetics of methylene blue removal from aqueous solution using gulmohar (Delonix regia) plant leaf powder: multivariate regression analysis," Journal of Hazardous Materials, vol. 169, no. 1-3, pp.119-127, 2009.

[14] A. Demirbas, "Agricultural based activated carbons for the removal of dyes from aqueous solutions: a review," Journal of Hazardous Materials, vol. 167, no. 1-3, pp. 1-9, 2009.

[15] A. E. Ofomaja, "Kinetics and mechanism of methylene blue sorption onto palm kernel fibre," Process Biochemistry, vol. 42, no. 1, pp. 16-24, 2007.

[16] M. Minamisawa, H. Minamisawa, S. Yoshida, and N. Takai, "Adsorption behavior of heavy metals on biomaterials," Journal of Agricultural and Food Chemistry, vol. 52, no. 18, pp. 56065611, 2004.

[17] F. A. Pavan, E. C. Lima, S. L. P. Dias, and A. C. Mazzocato, "Methylene blue biosorption from aqueous solutions by yellow passion fruit waste," Journal of Hazardous Materials, vol. 150, no. 3, pp. 703-712, 2008.

[18] M. T. Uddin, M. A. Islam, S. Mahmud, and M. Rukanuzzaman, "Adsorptive removal of methylene blue by tea waste," Journal of Hazardous Materials, vol. 164, no. 1, pp. 53-60, 2009.

[19] R. Han, W. Zou, W. Yu, S. Cheng, Y. Wang, and J. Shi, "Biosorption of methylene blue from aqueous solution by fallen phoenix tree's leaves," Journal of Hazardous Materials, vol. 141, no. 1, pp. 156-162, 2007.

[20] V. K. Garg, R. Gupta, A. B. Yadav, and R. Kumar, "Dye removal from aqueous solution by adsorption on treated sawdust," Bioresource Technology, vol. 89, no. 2, pp. 121-124, 2003.

[21] C. Namasivayam, D. Prabha, and M. Kumutha, "Removal of direct red and acid brilliant blue by adsorption on to banana pith," Bioresource Technology, vol. 64, no. 1, pp. 77-79, 1998.

[22] B. H. Hameed and A. A. Ahmad, "Batch adsorption of methylene blue from aqueous solution by garlic peel, an agricultural waste biomass," Journal of Hazardous Materials, vol. 164, no. 2-3, pp. 870-875, 2009.

[23] S. Jain and R. V. Jayaram, "Removal of basic dyes from aqueous solution by low-cost adsorbent: wood apple shell (Feronia acidissima)," Desalination, vol. 250, no. 3, pp. 921-927, 2010.

[24] M. Doğan, H. Abak, and M. Alkan, "Biosorption of methylene blue from aqueous solutions by hazelnut shells: equilibrium, parameters and isotherms," Water, Air, and Soil Pollution, vol. 192, no. 1-4, pp. 141-153, 2008.
[25] I. D. Mall, V. C. Srivastava, and N. K. Agarwal, "Removal of orange- $G$ and methyl violet dyes by adsorption onto bagasse fly ash-kinetic study and equilibrium isotherm analyses," Dyes and Pigments, vol. 69, no. 3, pp. 210-223, 2006.

[26] G. Crini and H. Ndongo Peindy, "Adsorption of C.I. basic blue 9 on cyclodextrin-based material containing carboxylic groups," Dyes and Pigments, vol. 70, no. 3, pp. 204-211, 2006.

[27] G. McKay, J. F. Porter, and G. R. Prasad, "The removal of dye colours from aqueous solutions by adsorption on low-cost materials," Water, Air, and Soil Pollution, vol. 114, no. 3-4, pp. 423-438, 1999.

[28] B. H. Hameed, "Spent tea leaves: a new non-conventional and low-cost adsorbent for removal of basic dye from aqueous solutions," Journal of Hazardous Materials, vol. 161, no. 2-3, pp. 753-759, 2009.

[29] M. Doğan, Y. Özdemir, and M. Alkan, "Adsorption kinetics and mechanism of cationic methyl violet and methylene blue dyes onto sepiolite," Dyes and Pigments, vol. 75, no. 3, pp. 701-713, 2007.

[30] K. V. Kumar and A. Kumaran, "Removal of methylene blue by mango seed kernel powder," Biochemical Engineering Journal, vol. 27, no. 1, pp. 83-93, 2005.

[31] D. K. Singh and B. Srivastava, "Removal of basic dyes from aqueous solutions by chemically treated psidium guyava leaves," Indian Journal of Environmental Health, vol. 41, no. 4, pp. 333345, 1999.

[32] F. Ferrero, "Dye removal by low cost adsorbents: Hazelnut shells in comparison with wood sawdust," Journal of Hazardous Materials, vol. 142, no. 1-2, pp. 144-152, 2007.

[33] R. Han, Y. Wang, P. Han, J. Shi, J. Yang, and Y. Lu, "Removal of methylene blue from aqueous solution by chaff in batch mode," Journal of Hazardous Materials, vol. 137, no. 1, pp. 550-557, 2006.

[34] G. Annadurai, R.-S. Juang, and D.-J. Lee, "Use of cellulose-based wastes for adsorption of dyes from aqueous solutions," Journal of Hazardous Materials B, vol. 92, no. 3, pp. 263-274, 2002.

[35] B. H. Hameed, D. K. Mahmoud, and A. L. Ahmad, "Equilibrium modeling and kinetic studies on the adsorption of basic dye by a low-cost adsorbent: coconut (Cocos nucifera) bunch waste," Journal of Hazardous Materials, vol. 158, no. 1, pp. 65-72, 2008.

[36] Y. S. Ho and G. McKay, "Sorption of dye from aqueous solution by peat," Chemical Engineering Journal, vol. 70, no. 2, pp. 115124, 1998.

[37] B. Acemioğlu, "Batch kinetic study of sorption of methylene blue by perlite," Chemical Engineering Journal, vol. 106, no. 1, pp. 73-81, 2005.

[38] M. Doǧan, M. Alkan, A. Türkyilmaz, and Y. Özdemir, "Kinetics and mechanism of removal of methylene blue by adsorption onto perlite," Journal of Hazardous Materials, vol. 109, no. 1-3, pp. 141-148, 2004.

[39] B. H. Hameed, A. L. Ahmad, and K. N. A. Latiff, "Adsorption of basic dye (methylene blue) onto activated carbon prepared from rattan sawdust," Dyes and Pigments, vol. 75, no. 1, pp. 143149, 2007.

[40] W. J. Weber and J. C. Morris, "Kinetics of adsorption on carbon from solution," Journal of Sanitary Engineering Division, vol. 89, pp. 31-60, 1963.

[41] G. Crini, "Kinetic and equilibrium studies on the removal of cationic dyes from aqueous solution by adsorption onto a cyclodextrin polymer," Dyes and Pigments, vol. 77, no. 2, pp. 415426, 2008.

[42] V. Ponnusami, R. Aravindhan, N. Karthik raj, G. Ramadoss, and S. N. Srivastava, "Adsorption of methylene blue onto gulmohar 
plant leaf powder: equilibrium, kinetic, and thermodynamic analysis," Journal of Environmental Protection Science, vol. 3, pp. $1-10,2009$.

[43] S. Wang and Z. H. Zhu, "Effects of acidic treatment of activated carbons on dye adsorption," Dyes and Pigments, vol. 75, no. 2, pp. 306-314, 2007.

[44] D. Suteu and T. Malutan, "Industrial cellolignin waste as adsorbent for methylene blue dye from aqueous solutions," BioResources, vol. 8, no. 1, pp. 427-446, 2013. 

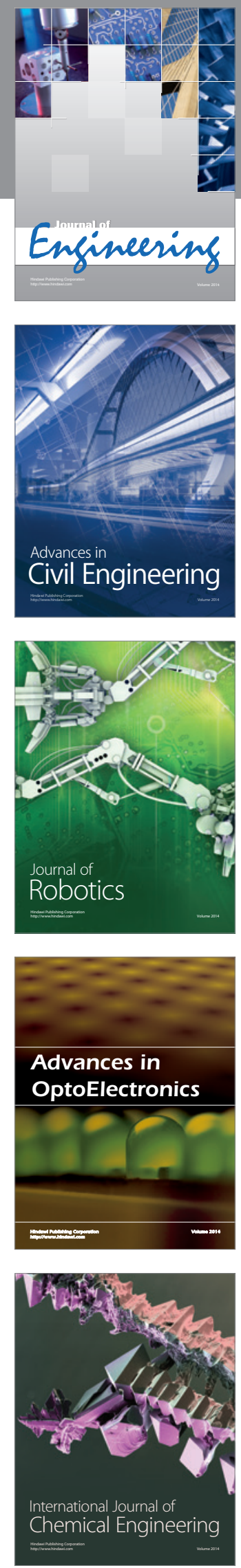

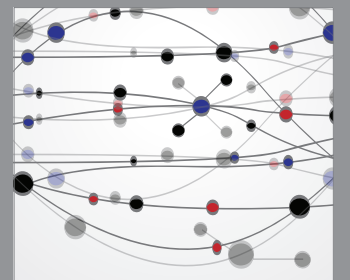

The Scientific World Journal
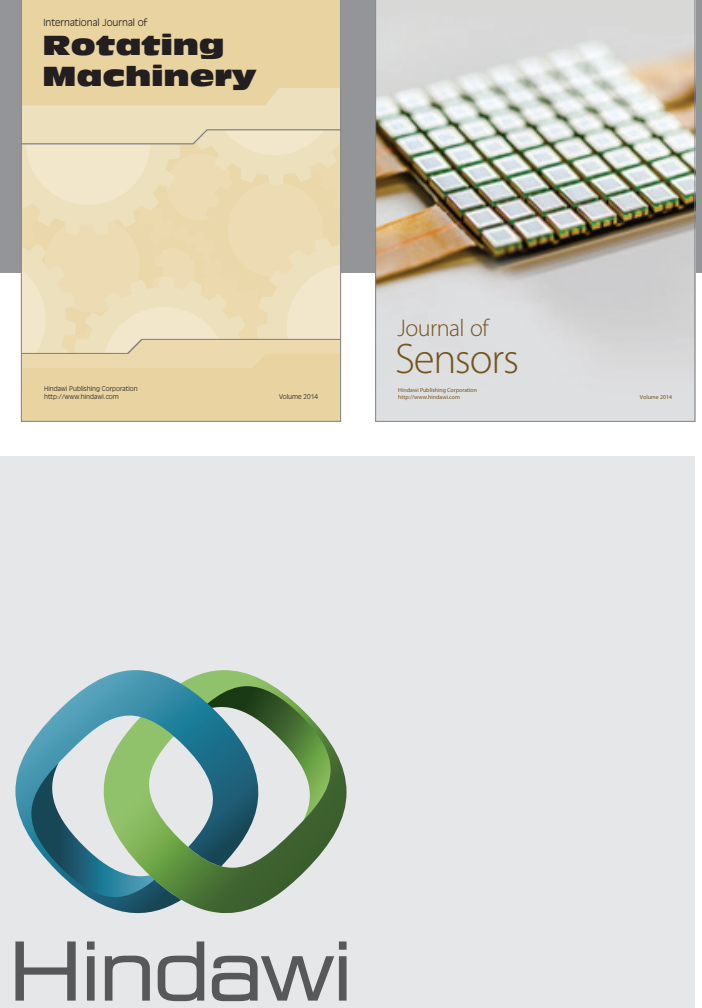

Submit your manuscripts at http://www.hindawi.com
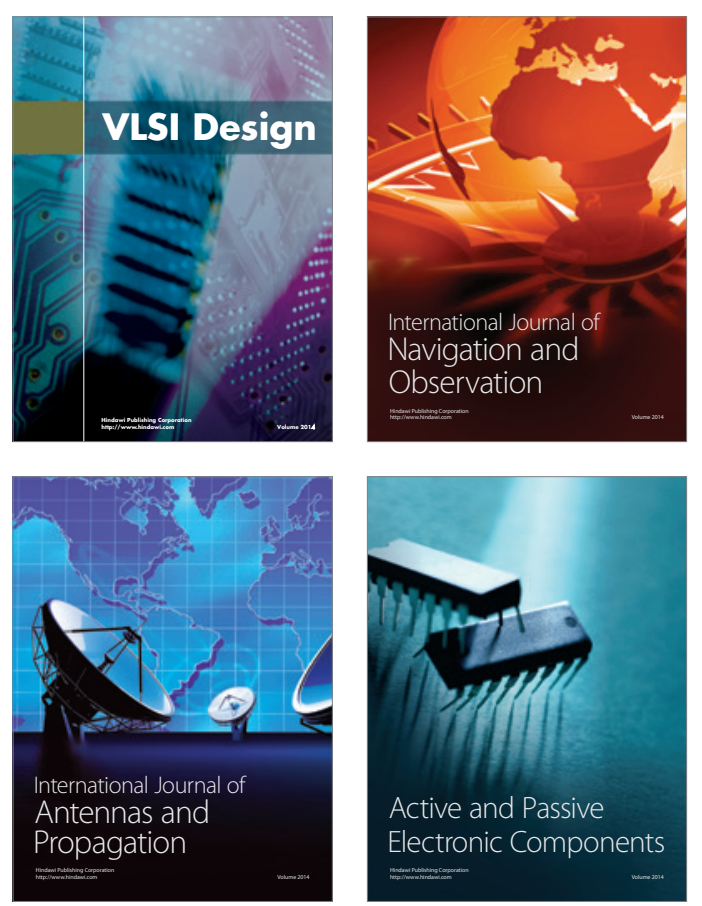
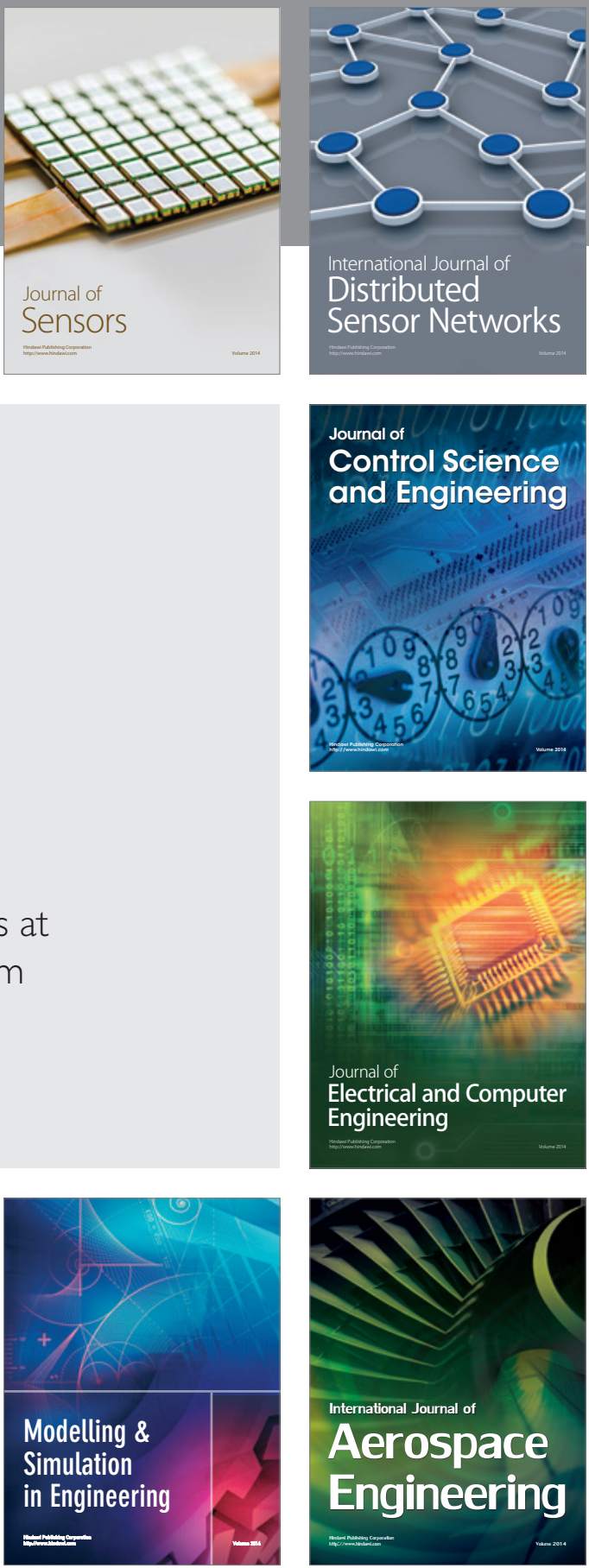

Journal of

Control Science

and Engineering
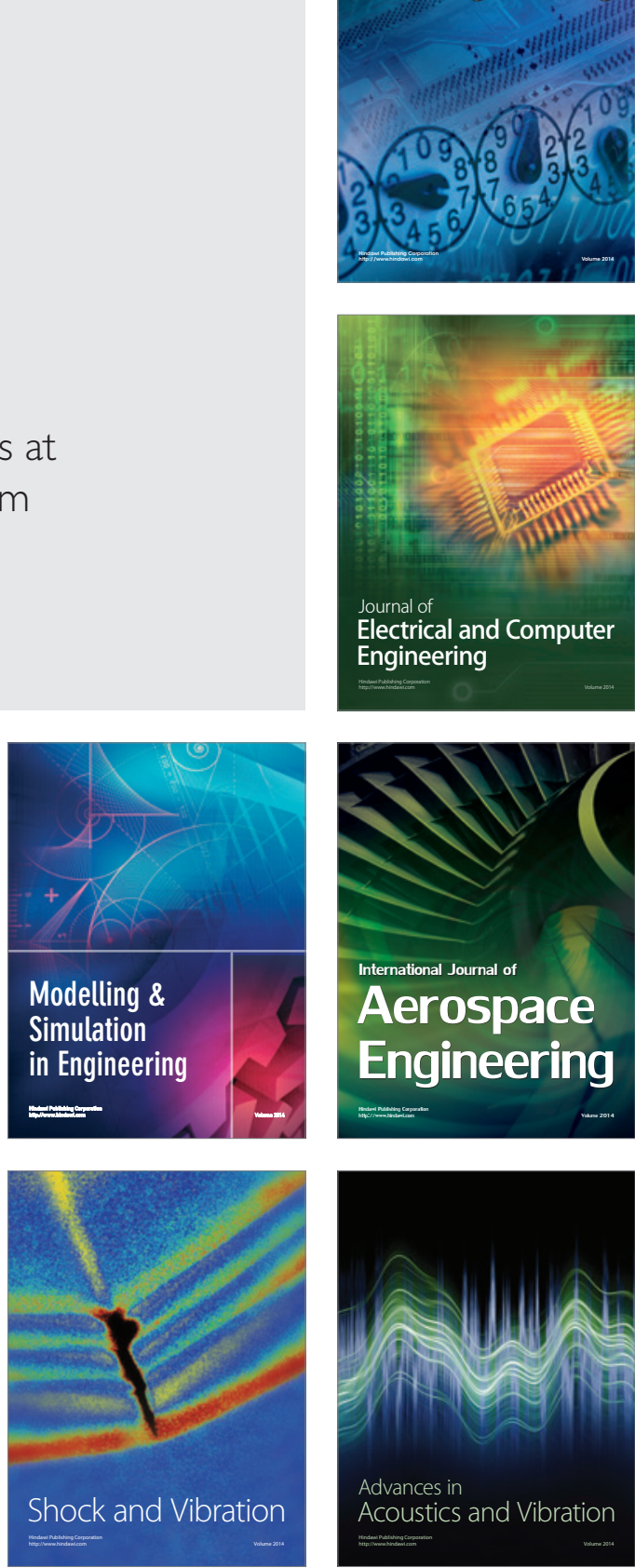